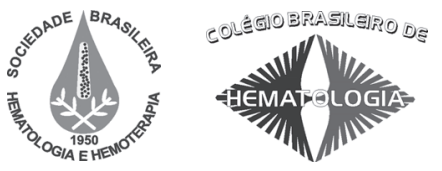

Review / Revisão

\title{
Linfoma Extranodal de Células NK/T tipo Nasal
}

\section{Extranodal Nasal type NK/T-Cell Lymphoma}

Carlos S. Chiattone

\section{Aspectos clínicos e epidemiológicos}

O Linfoma Extranodal de Células NK/T tipo Nasal (LNKTN) é uma doença rara na Europa e na América do Norte, mas é comum em países asiáticos e em populações nativas da America Central e América do Sul. Acomete principalmente pacientes adultos do sexo masculino. ${ }^{1}$ Embora a maioria dos linfomas sinonasais nos países ocidentais seja Linfoma Difuso de Grandes Células B, 40\% a 74\% dos linfomas sinonasais na Ásia são LNKTN. ${ }^{2,3}$

Em decorrência da sua apresentação clínica infiltrativa e destrutiva, da sua localização médio-facial, da dificuldade em se determinar claramente o mecanismo patofisiológico e da sua evolução constantemente fatal, esta doença recebeu ao longo dos anos uma série de diferentes denominações, sendo as mais conhecidas: "Granuloma Letal da Linha Média", "Granuloma Médio-Facial" e "Reticulose Polimorfa". Esta manifestação clínica tem como diagnóstico diferencial doenças infecciosas, granulomatosas, autoimunes e neoplá- sicas, como sífilis, leishmaniose, tuberculose, infecções fúngicas, granulomatose de Wegner, carcinoma e linfoma.

A classificação REAL foi a primeira a reconhecer esta entidade como doença linfoproliferativa, recebendo o nome de "Linfoma Angiocêntrico", pois o aspecto histológico frequentemente evidencia angiocentricidade e angioinvasão pelas células neoplásicas. Posteriormente se constatou que esta característica histopatológica não está sempre presente, sendo o termo linfoma angiocêntrico abandonado. Na classificação da OMS, de 2001, e na atual, de 2008, este linfoma foi denominado Linfoma Extranodal de Células NK/T tipo Nasal. ${ }^{1,2}$

A cavidade nasal e as áreas paranasais, incluindo o trato aerodigestivo alto, são os alvos de acometimento inicial desta doença em mais de $80 \%$ dos casos. ${ }^{1,4}$

Os sintomas iniciais mais frequentes são obstrução nasal, secreção nasal e epistaxe. Estas manifestações iniciais são muitas vezes indistinguíveis de sinusopatias inflamatórias ou infecciosas. À medida que a doença evolui ocorre 
edema, necrose e destruição óssea. A lesão nos casos avançados usualmente se infecta, o que, juntamente com a necrose, ocasionam intenso odor fétido. Este tipo de manifestação avançada com extensa necrose é hoje menos comum pois, com os recursos laboratoriais atuais, o diagnóstico é concluído mais rapidamente. Embora estes casos localmente avançados sejam atualmente menos frequentemente observados, quando ocorrem, é importante introduzir precocemente adequada cobertura antibiótica e proceder a desbridação da necrose antes do início da terapêutica químio/radioterápica. A não observância destes cuidados ocasiona muitas vezes a morte por sepse.

A doença, quando tem origem na região médio-facial, normalmente se mantém localizada nesta região, em estádio IE ou IIE, no caso de comprometimento de linfonodo regional. Nos casos onde ocorre disseminação, esta se faz com um padrão de homing peculiar para outras regiões extranodais, como pele, pulmão, trato gastrointestinal, rins, pâncreas, testículos e cérebro. ${ }^{1}$ Pode se disseminar também para fígado e baço. Quando a doença se inicia fora da região médiofacial, o local mais comum é a pele. Outros locais mais raros de doença extra médio-facial primária são os mesmos de disseminação da doença médio-facial. Como este linfoma se manifesta principalmente como doença extranodal, o estádio III é raro, sendo a maioria das doenças avançadas observadas em estádio IV.

Quando a doença progride é comum o aparecimento de sintomas gerais como febre, coagulação intravascular disseminada e síndrome hematofagocítica. A síndrome hematofagocítica geralmente cursa com pancitopenia, sendo diagnóstico diferencial de infiltração linfomatosa da medula óssea. Quando a doença é avançada, comumente o estado geral do paciente é muito comprometido, algumas vezes impedindo o tratamento neoplásico específico.

\section{Aspectos morfológicos e imunofenotípicos}

Histologicamente, o LNKTN é caracterizado por infiltrado polimorfo composto por uma mistura de pequenos linfócitos de aparência normal e células linfoides atípicas de tamanhos variados, de permeio a plasmócitos, eosinófilos e histiócitos. Um aspecto característico é a invasão da parede vascular e a oclusão vascular por células com grau variável de atipia. No entanto, como já foi salientado, este aspecto, embora muito característico, não está presente em todos os casos. $^{4}$

Usualmente se observa uma proeminente necrose isquêmica das células neoplásicas e do tecido normal. A presença de necrose no material histológico ocasiona grande dificuldade para o patologista. Por este motivo é necessário o recurso de um otorrinolaringologista experiente para uma biópsia ampla e em local bem selecionado. É comum, quando estes cuidados não são observados, a necessidade de múltiplas biópsias até o diagnóstico definitivo. ${ }^{5}$
Como está altamente relacionado, o achado do vírus Epstein-Barr por hibridação in situ fortalece o diagnóstico. ${ }^{1}$

A identificação do envolvimento da medula óssea também pode ser facilitado pela pesquisa do EBV por hibridização in situ. Por este motivo, alguns autores sugerem que a pesquisa do EBV na medula óssea seja feita rotineiramente.

Estudos recentes têm sugerido que a carga viral do EBV possa ter impacto prognóstico, além de poder ser útil no acompanhamento da resposta terapêutica. ${ }^{6}$

O imunofenótipo do LNKTN é semelhante ao de células NK. As células neoplásicas normalmente são CD2+, CD56+, $\mathrm{CD} 3$ superfície -, $\mathrm{CD} 3$ citoplasmático +. São tipicamente CD4 e CD8 -, mas podem expressar CD4, CD8 e/ou CD7. A maioria dos casos expressa grânulos citotóxicos como granzima B, perfurina e TIA-1.?

Os genes de receptores de célula $\mathrm{T}$ e de imunoglobulinas geralmente não estão rearranjados. ${ }^{7}$

\section{Diagnóstico}

As características clínicas e localização peculiares deste linfoma têm grande relevância na conclusão do diagnóstico final. Como a morfologia das células neoplásicas é muito variável, é aconselhável considerar este diagnóstico em todos os casos de linfoma agressivo extranodal associado a angiocentricidade, angioinvasão e necrose. A chave para o diagnóstico, no entanto, é a demonstração de marcadores celulares NK/T e a identificação do vírus Epstein-Barr.

Cerca de 95\% dos casos são de origem NK, expressando positividade para CD2, CD3 citoplasmático, CD56 e grânulos citotóxicos, sendo negativo para $\mathrm{CD} 3$ de superfície. $\mathrm{Na}$ maioria dos casos, principalmente nos de localização médio-facial, o vírus Epstein-Barr pode ser identificado por hibridização in situ .

A granulomatose linfomatoide (GL), outra doença linfoproliferativa associada ao EBV, que se apresenta em localização extranodal, pode ter aspecto histológico semelhante, mas na GL as células neoplásicas EBV positivas são linfócitos $\mathrm{B}$, sendo então positivas para marcadores pan-B, como CD20. ${ }^{8}$

\section{Prognóstico e tratamento}

Mais de $60 \%$ dos pacientes em estádio IE se mantém em remissão por longo prazo quando submetidos a tratamento radioterápico, com ou sem quimioterapia. Por outro lado, pacientes com doença mais avançada, em estádio IIE ou IV, têm um prognóstico muito pior, com recidiva local ou em outras regiões extranodais. ${ }^{9}$

Os Linfomas Extranodais de Células NK/T tipo Nasal que se originam fora da região médio-facial têm um prognóstico pior. Mas, como o LNKTN é uma entidade descrita relativamente há pouco tempo pela classificação da OMS, o prognóstico e a melhor estratégia de tratamento ainda precisam ser melhor definidas. 
Diversos grupos com experiência mais consolidada têm documentado a pobre evolução destes linfomas, com sobrevida global em cinco anos, variando de 37,9\% a 45\%. ${ }^{10,11}$

O valor do Índice Prognóstico Internacional (IPI) na estratificação prognóstica deste linfoma tem sido motivo de controvérsia. Mesmo que o IPI seja aplicável, apenas uma pequena proporção dos pacientes $(0 \%$ a $7 \%)$ é classificada como grupo de alto risco. Estes dados apontam para a necessidade de se identificarem outros fatores prognósticos.

Diversas variáveis têm sido relacionadas a pior prognóstico, como envolvimento de linfonodo regional, elevação de DHL, pobre performance status, extensão paranasal, sintomas B, Ki-67 elevado, expressão de Cox-2 e carga viral do vírus Epstein-Barr, ${ }^{12-16}$ entre outros.

Diversos modalidades terapêuticas têm sido propostas para o LNKTN, desde radioterapia isolada até quimioterapia em altas doses com transplante de células-tronco hematopoéticas.

Em decorrência da raridade da doença, é difícil a realização de estudo prospectivo randomizado, sendo a maioria dos dados disponíveis na literatura provenientes de análises restrospectivas.

Pacientes com estádio IE frequentemente respondem à radioterapia isolada, com taxa de resposta completa ao redor de $70 \%$. Entretanto, a sobrevida de longo prazo geralmente é baixa, em decorrência de frequente recidiva sistêmica. Quimioterapia isolada resulta em menor taxa de resposta completa, ao redor de $40 \%$ a $45 \%$. Embora usada rotineiramente, o benefício da terapia combinada - quimioterapia associada a radioterapia - ainda precisa ser comprovado. Alguns autores sugerem a vantagem na utilização da radioterapia previamente à quimioterapia.

O LNKTN disseminado requer tratamento quimioterápico. Embora a doença seja usualmente refratária a esquemas com antraciclina, o esquema CHOP é habitualmente o mais utilizado, mas a taxa de resposta completa é baixa, variando entre $25 \%$ e $40 \%$, seguindo uma evolução muito agressiva. Recentemente, tratamento quimioterápico incluindo Laspararginase, inicialmente utilizado em recidiva, tem sido testado em primeira linha. ${ }^{17}$

Atualmente não existe um tratamento standard para o LNKTN; estudos com pequeno número de pacientes sugerem que transplante com células-tronco hematopoéticas possa ser promissor. ${ }^{18}$

\section{Abstract}

Extranodal Nasal type NK/T-Cell Lymphoma has a peculiar geographic distribution, occurring more frequently in Eastern countries and in the native populations of some Central and South American countries. It is commonly found in the nasal cavity and paranasal sinuses, but may also compromise other structures in the mid-facial region. The disease has a characteristic homing dissemination pattern, including skin, testis, CNS and digestive tract. This lymphoma can, less frequently, primarily compromise these regions. The majority of these neoplastic diseases present an NK phenotype, but a few cases can be truly of T-cell origin, because of which it is designed "NK/T-cell lymphoma". The Epstein-Barr virus genome can be detected in most of the cases, suggesting an etiological relationship. Although this lymphoma is responsive to radiotherapy, it is more resistant to conventional chemotherapy than other lymphomas. A possible explanation for this is the frequent expression of the p-glycoprotein. The prognosis of these lymphomas is still poor, making further investigation of new therapies imperativ. Rev. Bras. Hematol. Hemoter. 2009;31(Supl. 2):26-29

Key words: Extranodal Nasal type NK/T-Cell Lymphoma; extranodal lymphoma; Epstein-Barr virus.

\section{Referências Bibliográficas}

1. Suzuki R, Takeuchi K, Ohshima K, Nakamura S. Extranodal NK/ T-cell lymphoma: diagnosis and treatment cues. Hematol Oncol. 2008;26(2):66-72.

2. Ko YH, Kim CW, Park CS, Jang HK, Lee SS, Kim SH, et al. REAL classification of malignant lymphomas in the Republic of Korea: incidence of recently recognized entities and changes in clinicopathologic features. Hematolymphoreticular Study Group of the Korean Society of Pathologists. Revised European-American lymphoma. Cancer. 1998;83(4):806-12.

3. Au WY, Ma SY, Chim CS, Choy C, Loong F, Lie AK, et al. Clinicopathologic features and treatment outcome of mature Tcell and natural killer-cell lymphomas diagnosed according to the World Health Organization classification scheme: a single center experience of 10 years. Ann Oncol. 2005;16(2):206-14.

4. Jaffe ES. Classification of natural killer (NK) cell and NK-like Tcell malignancies. Blood. 1996;87(4):1207-10.

5. Jaffe ES, Chan JK, Su IJ, Frizzera G, Mori S, Feller AC, et al. Report of the Workshop on Nasal and Related Extranodal Angiocentric T/Natural Killer Cell Lymphomas. Definitions, differential diagnosis, and epidemiology. Am J Surg Pathol. 1996; 20(1):103-11.

6. Hsieh PP, Tung CL, Chan AB, Liao JB, Wang JS, Tseng HH, et al. EBV viral load in tumor tissue is an important prognostic indicator for nasal NK/T-cell lymphoma. Am J Clin Pathol. 2007;128 (4): $579-84$

7. Ferry JA, Sklar J, Zukerberg LR, Harris NL. Nasal lymphoma. A clinicopathologic study with immunophenotypic and genotypic analysis. Am J Surg Pathol. 1991;15(3):268-79.

8. Myers JL, Kurtin PJ, Katzenstein AL, Tazelaar HD, Colby TV, Strickler JG, et al. Lymphomatoid granulomatosis. Evidence of immunophenotypic diversity and relationship to Epstein-Barr virus infection. Am J Surg Pathol. 1995;19(11):1300-12.

9. Li YX, Yao B, Jin J, Wang WH, Liu YP, Song YW, et al. Radiotherapy as primary treatment for stage IE and IIE nasal natural killer/T-cell lymphoma. J Clin Oncol. 2006; 24(1):1 $81-9$.

10. Lee J, Park YH, Kim WS, Lee SS, Ryoo BY, Yang SH, et al. Extranodal nasal type NK/T-cell lymphoma: elucidating clinical prognostic factors for risk-based stratification of therapy. Eur $\mathrm{J}$ Cancer. 2005;41(10):1402-8.

11. Chim CS, Ma SY, Au WY, Choy C, Lie AK, Liang R, et al. Primary nasal natural killer cell lymphoma: long-term treatment outcome and relationship with the International Prognostic Index. Blood. 2004;103(1):216-21. 
12. You JY, Chi KH, Yang MH, Chen CC, Ho CH, Chau WK, et al. Radiation therapy versus Radiation therapy versus chemotherapy as initial treatment for localized nasal natural killer (NK)/T-cell lymphoma: a single institute survey in Taiwan. Ann Oncol. 2004;15(4):618-25.

13. Au WY, Pang A, Choy C, Chim CS, Kwong YL. Quantification of circulating Epstein-Barr virus (EBV) DNA in the diagnosis and monitoring of natural killer cell and EBV-positive lymphomas in immunocompetent patients. Blood. 2004;104(1):243-9.

14. Lee J, Park YH, Kim WS, Lee SS, Ryoo BY, Yang SH, et al. Extranodal nasal type NK/T-cell lymphoma: elucidating clinical prognostic factors for risk-based stratification of therapy. Eur $\mathrm{J}$ Cancer. 2005;41(10):1402-8.

15. Lee J, Suh C, Park YH, Ko YH, Bang SM, Lee JH, et al. Extranodal natural killer T-cell lymphoma, nasal-type: a prognostic model from a retrospective multicenter study. J Clin Oncol. 2006; 24(4):612-8.

16. Kim SJ, Kim BS, Choi CW, Choi J, Kim I, Lee YH, et al. Ki-67 expression is predictive of prognosis in patients with stage I/II extranodal NK/T-cell lymphoma, nasal type. Ann Oncol. 2007;18(8):1382-7.

17. Yong $\mathrm{W}$, Zheng $\mathrm{W}$, Zhu J, Zhang $\mathrm{Y}$, Wei $\mathrm{Y}$, Wang X, et al. Midline NK/T-cell lymphoma nasal-type: treatment outcome, the effect of L-asparaginase based regimen, and prognostic factors. Hematol Oncol. 2006;24(1):28-32.

18. Suzuki R, Suzumiya J, Nakamura S, Kagami Y, Kameoka JI, Saka $\mathrm{C}$, et al. Hematopoietic stem cell transplantation for natural killer-cell lineage neoplasms. Bone Marrow Transplant. 2006; 37(4):425-31.

O tema apresentado foi proposto pela Organização do $8^{\circ}$ Simpósio da Associação Ítalo-Brasileira de Hematologia, realizado durante o

XIII Congresso de Transplante de Medula Óssea.

Publicado após concordância do editor.

Conflito de interesse: sem conflito de interesse

Recebido: 25/06/2009

Aceito: 08/07/2009 